Nenad Kostić

Mirko Blagojević

Nenad Petrović

Miloš Matejić

Nenad Marjanović

https://doi.org/10.21278/TOF.42102

ISSN 1333-1124

eISSN 1849-1391

\title{
DETERMINATION OF REAL CLEARANCES BETWEEN CYCLOIDAL SPEED REDUCER ELEMENTS BY THE APPLICATION OF HEURISTIC OPTIMIZATION
}

\begin{abstract}
Summary
The actual cycloidal speed reducer elements differ from their theoretical ideal due to existing tolerances; therefore, the cycloid disc behaves like a corrected one. This study is oriented towards determining contacts in corrected cycloid speed reducer profiles from the aspect of geometry. Based on this geometry, an objective function was developed for the optimization with some limitations. Heuristic optimization was used to determine the position of the cycloidal drive elements when a contact was established and, consequently, to determine clearances in other places. Some limitations were set so that the model could reflect a real contact. In this study, a TLBO algorithm was used for the optimization of a cycloidal speed reducer. Clearances were analysed for different correction values of the cycloid disc profile of an actual cycloidal drive and the optimization procedure was presented. The results provide a real picture of the contact in the presence of inevitable machining tolerances.
\end{abstract}

Key words: $\quad$ cycloidal speed reducer, profile correction, contact, heuristic optimization, teaching-learning-based optimization (TLBO)

\section{Introduction}

Due to their extremely favourable performance properties (high efficiency, compact design, high gear ratio, easy maintenance, reliable operation, etc.) cycloidal speed reducers are frequently used in modern industry. Their application in the renewable energy sources is especially notable. The most commonly used cycloidal speed reducer gear profile is an equidistant shortened epitrochoid [1,2,3], although profile modifications can sometimes be made in order to achieve better performance $[4,5,6]$. The geometry of the cycloidal gearing has been well studied, and there is a variety papers dealing with this issue, [7,8,9,10]. Some authors have also defined procedures for parametric drawing of the cycloid disc tooth profile (2D and 3D), which significantly facilitates the design process of a cycloidal speed reducer, $[11,12,13]$. As part of multicriteria optimization of the basic cycloidal speed reducer parameters, special attention was paid to obtaining an optimal cycloid disc tooth profile. 
Efficiency and stress distribution [14,15] have also been optimized, as well as other geometric and exploitation parameters.

In order to make a good cycloidal speed reducer even more compact, dynamically more stable and reliable, some authors have defined various new designs of cycloidal speed reducers, $[16,17,18,19]$.

Almost all theoretical analyses of the cycloidal speed reducer assume that all the cycloid disc teeth are in contact with the corresponding ring gear rollers and that half of them carry the load, [20]. However, this is not the case with actual cycloidal speed reducers because there are certain clearances between the cycloid disc teeth and the ring gear rollers, which compensate for manufacturing errors, ensure better lubrication, and also to enable mounting and dismounting procedures. The fact that half of the cycloid disc teeth do not carry the load has opened an entirely new area of research in the study of cycloidal speed reducers.

In their studies, J.G. Blanche and D.C.H. Yang [21,22] investigated the influence of clearances on the torque ripple, gear ratio, and other parameters of the cycloidal speed reducer. The researchers defined the functional relations between the driving angle and the analysed output gear parameters. They introduced the notion of the lag angle and derived mathematical expressions needed to calculate it.

Li Lixing defined numerous mathematical models to calculate the size of the clearance between the cycloid disc teeth and the ring gear rollers, as well as the size of elastic deformations of the elements that are engaged in the load transmission, [23]. Li Lixing also studied the forces that affect the cycloid disc teeth in the presence of clearances.

Kao, Hsieh and Lee developed a computer programme for the kinematic error analysis of a two-stage cycloidal drive, [24]. The fact that this application is directly connected to CAD software makes this paper even more significant.

Multicriteria optimization of planetary transmissions applicable in industry has been the object of investigation of many scientists, [25,26,27,28,29].

Nowadays, advanced heuristic algorithms are used in engineering optimization, as it is the case in this study which uses a modern metaheuristic optimization technique called Teaching-Learning-Based Optimization (TLBO) developed and tested by $R$. $V$. Rao et al. [30]. Rao et al. also applied this algorithm to actual engineering problems [31].

Taking into consideration the number of papers dealing with cycloidal speed reducers, it can be concluded that this type of mechanical gears has not been adequately addressed in theory, which is certainly reflected in their performance characteristics. This is mainly due to the complexity of the analysis involved. Among other things, the practical application of cycloidal speed reducers includes a complex analysis of the clearances between the cycloid disc teeth and the ring gear rollers. Heuristic optimizations were chosen in this paper because of the difficulty of the studied problem, a large number of extreme values, and the process complexity. Heuristic optimization methods typically provide optimal solutions when there are few known facts about the problem, which is primarily a result of manufacturing and technological limitations. Therefore, any advances in the determination of the clearance between these elements can be a significant contribution to the field of cycloidal speed reducers.

\section{Description of the problem}

There is a significant difference between a theoretical model and an actual cycloidal speed reducer. Until now, it has not been possible to design a theoretical model in practice. This is mostly because of the clearances between the ring gear rollers and the cycloid disc which are a result of manufacturing tolerance and errors. The tolerance compensates for the 
errors made in the manufacture of cycloid discs, while the clearance enables better lubrication of the elements and facilitates the mounting and dismounting of the cycloidal speed reducer. The main disadvantage is the fact that the theoretical contact of a great number of elements is lost in the presence of clearances, leaving only one roller of the cycloidal speed reducer in contact with the cycloid disc. This radically changes the gear characteristics compared to the theoretical ones, and heightens the need to study the clearances between the elements of the cycloidal speed reducer in relation to the tolerance.

The clearance between the rollers and the cycloid disc is achieved in several ways [22]:

- by correcting the cycloid disc profile,

- by increasing the diameter of the circle with rollers,

- by decreasing the diameter of the rollers.

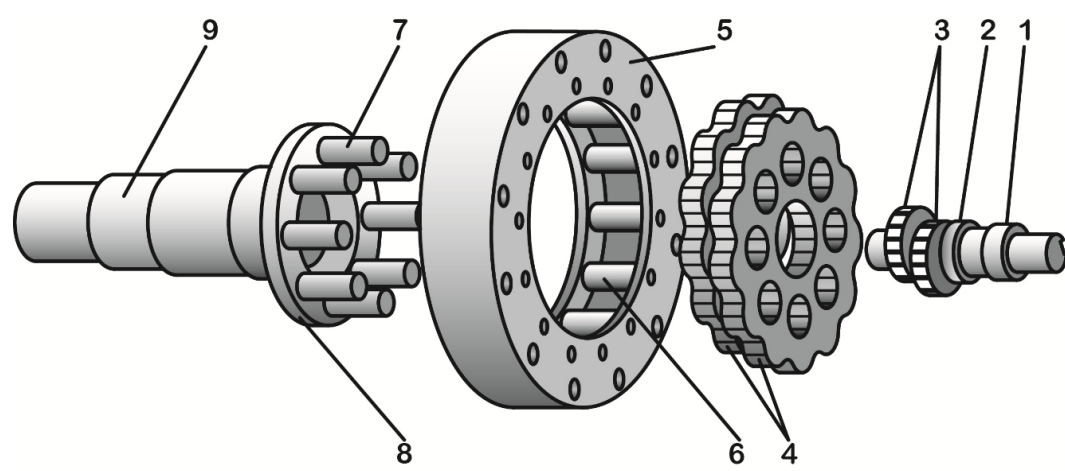

Fig. 1 The structure of cycloid drive (1 - Input shaft; 2 - Eccentric; 3 - Bearings; 4 - Cycloid discs; 5 - Ring gear; 6 - Ring gear rollers; 7 - Output rollers; 8 - Carrier; 9 - Output shaft) [10]

The curve that defines the cycloid disc profile (the equidistant shortened epitrochoid) can be given in a mathematical form [10], as seen in the expression (1). It is important to point out that the determination of clearances between the cycloidal speed reducer elements is based on geometry; therefore, it is necessary to analyse the problem using the equations that formulate the problem geometrically.

$$
\begin{aligned}
& x_{c}=\left(R_{b}+R_{a}\right) \cdot \cos \alpha+e \cdot \cos (\alpha+\beta)-q \cdot \cos (\alpha+\phi), \\
& y_{c}=\left(R_{b}+R_{a}\right) \cdot \sin \alpha+e \cdot \sin (\alpha+\beta)-q \cdot \sin (\alpha+\phi) .
\end{aligned}
$$

where:

$R_{a}-$ the radius of the rolling circle,

$R_{b}$ - the radius of the base circle,

$\alpha$ - the angular position of the starting contact point and the current contact point of the base and the rolling circle in relation to the centre of the base circle,

$\beta$ - the swivel angle of the rolling circle (Figure 2),

$e$ - eccentricity,

$q$ - the radius of the ring gear roller - equidistant distance,

$\phi-$ the auxiliary angle.

The profile of the equidistant shortened epitrochoid (1) is obtained using the values given in Fig. 2, which shows the procedure of generating the curve of the equidistant shortened epitrochoid. $K_{b}$ stands for the base circle (Fig. 2), $K_{a}$ for the rolling circle, and $\lambda$ for the auxiliary angle for the starting position. 
N. Kostić, M. Blagojević, N. Petrović,

M. Matejić, N. Marjanović
Determination of Real Clearances Between

Cycloidal Speed Reducer Elements by the Application of Heuristic Optimization

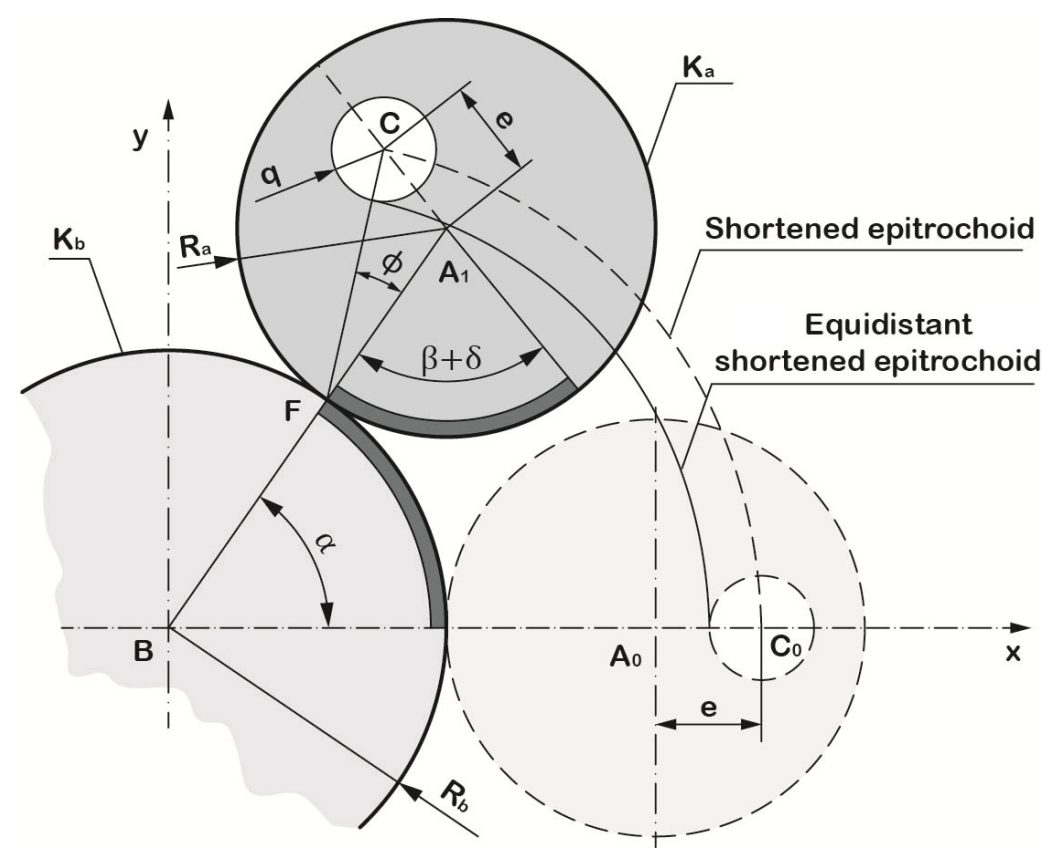

Fig. 2 Generation of the equidistant shortened epitrochoid

The presented equation defines the profile of the equidistant shortened epitrochoid, which constitutes the gear tooth profile. In order to generate an adequate mathematical model, this equation can be presented in a slightly different form. Since it is known that

$$
\begin{aligned}
& \beta=\frac{R_{b}}{R_{a}} \cdot \alpha, \\
& \phi=\arctan \left(\frac{\sin \left(\frac{R_{b}}{R_{a}} \cdot \alpha\right)}{\frac{R_{a}}{e}+\cos \left(\frac{R_{b}}{R_{a}} \cdot \alpha\right)}\right) .
\end{aligned}
$$

Based on the equations (1) and (2), one can write:

$$
\begin{aligned}
& x_{c}=\left(R_{b}+R_{a}\right) \cdot \cos \alpha+e \cdot \cos \left(\alpha+\frac{R_{b}}{R_{a}} \cdot \alpha\right)-q \cdot \cos \left(\alpha+\arctan \left(\frac{\sin \left(\frac{R_{b}}{R_{a}} \cdot \alpha\right)}{\frac{R_{a}}{e}+\cos \left(\frac{R_{b}}{R_{a}} \cdot \alpha\right)}\right)\right), \\
& y_{c}=\left(R_{b}+R_{a}\right) \cdot \sin \alpha+e \cdot \sin \left(\alpha+\frac{R_{b}}{R_{a}} \cdot \alpha\right)-q \cdot \sin \left(\alpha+\arctan \left(\frac{\sin \left(\frac{R_{b}}{R_{a}} \cdot \alpha\right)}{\frac{R_{a}}{e}+\cos \left(\frac{R_{b}}{R_{a}} \cdot \alpha\right)}\right)\right) .
\end{aligned}
$$

The mathematical model is formulated based on the equations denoted by (3). Clearances in the cycloidal speed reducer elements are determined using this mathematical model and verified using optimization methods.

\section{Mathematical model}

Since clearances are minimal distances between the rollers of the cycloidal speed reducer ring gear and the cycloid disc, it is necessary to create a mathematical model that will reflect these distances. It is also necessary to minimize the goal function. The mathematical 
model is an original approach developed on the basis of geometry of the cycloidal speed reducer elements. The basis of the theoretical model defines the contact of all the cycloid disc teeth with the cycloidal speed reducer rollers, as shown in Fig. 3 a). It is possible to set the equidistant distance in relation to the gear curve; this distance goes through the centres of all the rollers, Fig. 3 b).

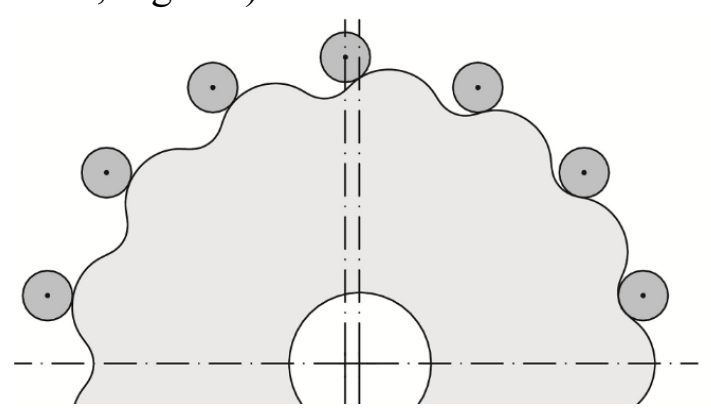

a)

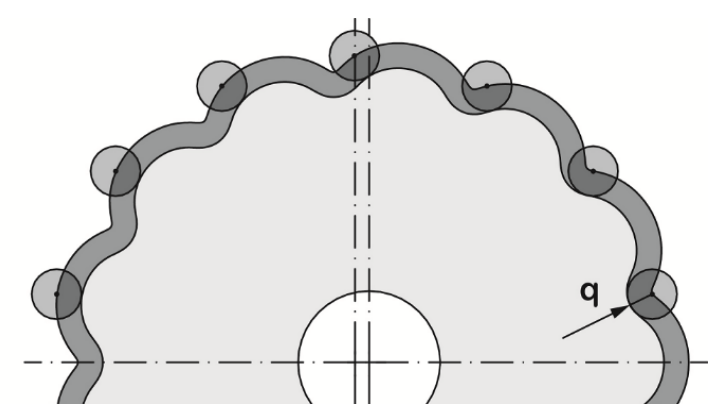

b)

Fig. 3 a) Theoretical contact of the cycloidal speed reducer elements; b) The equidistant position of the cycloid disc which goes through the centres of all the rollers.

The mathematical model has been created in such a way that the distance from the roller centre point and the curve of the cycloid disc of the cycloidal speed reducer can be determined. Correcting the curve profile of the cycloid disc, each of the roller centres is placed at the same distance from the cycloid disc curve, Fig. 4 a). In order for the gear to be functional, the cycloid disc needs to be in contact with at least one roller, Fig. $4 \mathrm{~b}$ ). The mathematical model has been developed in such a way that the cycloid disc centres can move along the circle with the rollers until the actual contact has been realized.

The following expression is the basis for the formulation of the mathematical model:

$$
\min \sqrt{X^{2}+Y^{2}}
$$

The expression (4) represents an approach used for determining the geometric distance between the cycloid disc and the ring gear rollers. This expression involves the minimal distance between the elements, and the coordinates represent the distances between the elements along the $X$ and $Y$ axes.

$$
\begin{aligned}
& X=x_{r}-x_{c}, \\
& Y=y_{r}-y_{c} .
\end{aligned}
$$

where:

$$
\begin{aligned}
& x_{r}=\left(R_{b}+R_{a}\right) \cdot \cos (\eta+n \cdot \theta), \\
& y_{r}=\left(R_{b}+R_{a}\right) \cdot \sin (\eta+n \cdot \theta),
\end{aligned}
$$

$$
\begin{aligned}
& x_{c}=\left(R_{b}+R_{a}\right) \cdot \cos (\alpha)+e \cdot \cos \left(\alpha+\frac{R_{b}}{R_{a}} \cdot \alpha\right)-\left(q-q_{c}\right) \cdot \cos \left(\alpha+\arctan \left(\frac{\sin \left(\frac{R_{b}}{R_{a}} \cdot \alpha\right)}{\frac{R_{a}}{e}+\cos \left(\frac{R_{b}}{R_{a}} \cdot \alpha\right)}\right)\right), \\
& y_{c}=\left(R_{b}+R_{a}\right) \cdot \sin (\alpha)+e \cdot \sin \left(\alpha+\frac{R_{b}}{R_{a}} \cdot \alpha\right)-\left(q-q_{c}\right) \cdot \sin \left(\alpha+\arctan \left(\frac{\sin \left(\frac{R_{b}}{R_{a}} \cdot \alpha\right)}{\frac{R_{a}}{e}+\cos \left(\frac{R_{b}}{R_{a}} \cdot \alpha\right)}\right)\right) .
\end{aligned}
$$


N. Kostić, M. Blagojević, N. Petrović, M. Matejić, N. Marjanović
Determination of Real Clearances Between Cycloidal Speed Reducer Elements by the Application of Heuristic Optimization

$\eta$ - the optimization variable, defining the angle of the centre of the roller meshing with the cycloid disc in relation to the horizontal axis,

$n$ - the ordinal number of the roller for which the distance is calculated; when the contact is established, the value is 0 ,

$\theta=2 \pi / z_{2}-$ the angle at which the rollers are turned $\left(z_{2}=\right.$ the total number of rollers),

$q_{c}$ - the radius of the corrected ring gear roller - corrected equidistant distance.

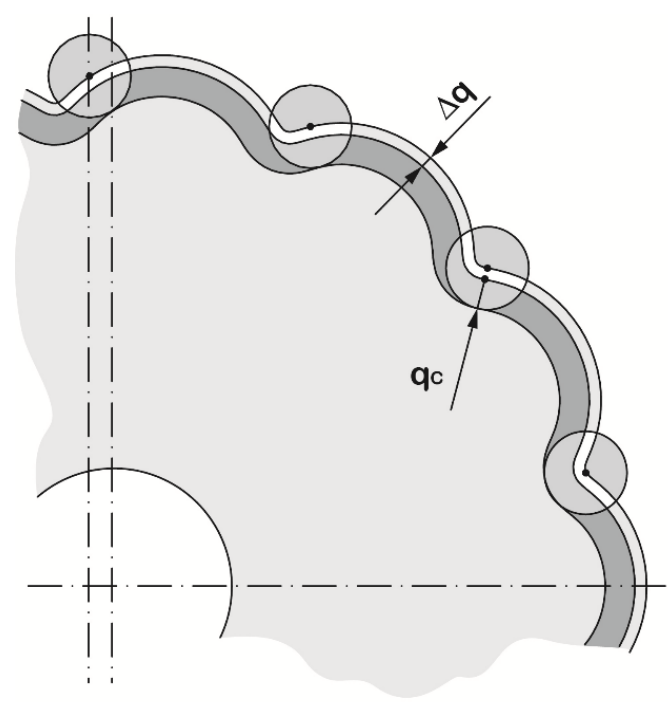

a)

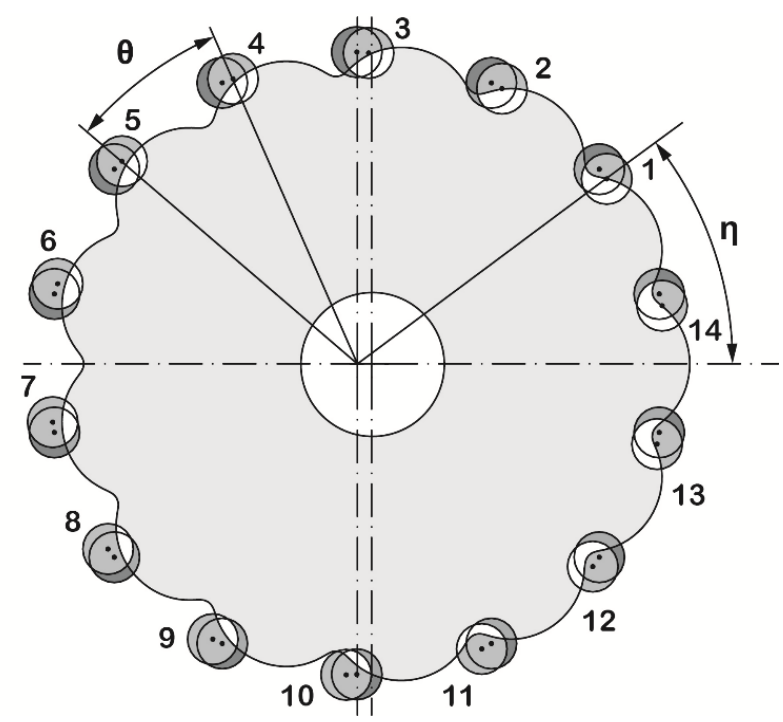

b)

Fig. 4 a) The profile correction - the equidistant distance from the centre of the roller; b) Turning of the roller centres along the circle until the contact has been established.

The subscript $r$ refers to the roller, while the subscript $\mathrm{c}$ refers to the cycloid disc. These values are presented in Figures $4 \mathrm{a}$ ) and $4 \mathrm{~b}$ ).

The optimization variables include the angle of the starting contact point and the current contact point of the base circle and the rolling circle in relation to the centre of the base circle (Figure 2), with the interval of $0 \leq \alpha \leq 2 \pi$, as well as the variable that defines the values of the angle of the centre of the roller meshing with the cycloid disc in relation to the horizontal axis, at the interval of $0 \leq \eta \leq 2 \pi$.

The value of the equidistance between the cycloid disk and the centre of the ring gear roller that needs to be minimized is given in Figure 5. The minimal value of this distance can be 0 , which is actually the contact between the corrected profile of the cycloid disc and the ring gear roller.

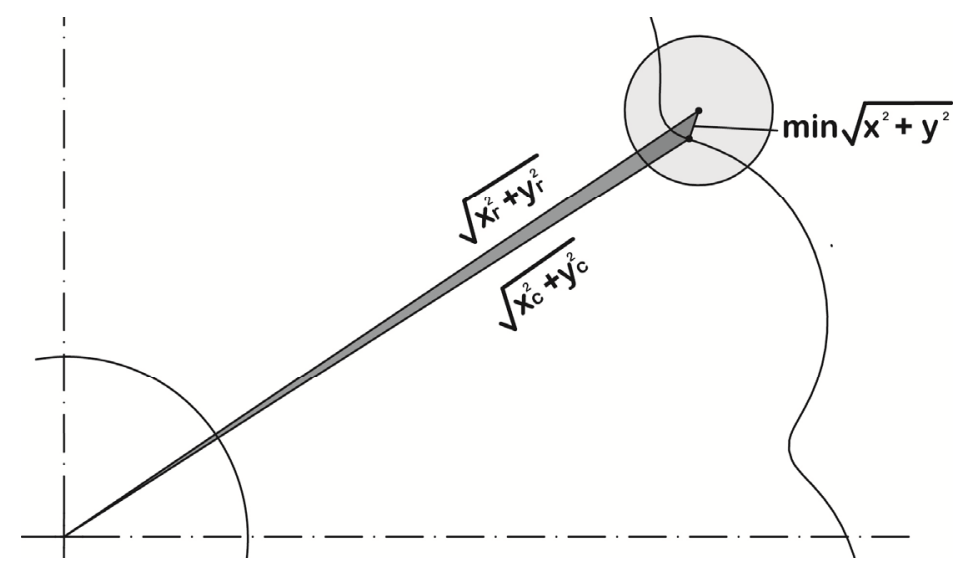

Fig. 5 The equidistance between the cycloid disc and the centre of the ring gear roller that needs to be minimized 
The contact between the cycloid disc and the ring gear roller can be determined by applying the defined mathematical model from the equation (5). However, it is also necessary to determine acceptable solutions, i.e. the solutions when none of the elements will overlap for any of the rollers. This approach yields a set of potential solutions that need to be studied and verified. If only the goal function were applied, with no limitations, overlapping between the elements would probably occur and this would not be a realistic case. That is why limitations are essential for the validation of this approach.

\section{TLBO algorithm}

Teaching-Learning-Based Optimization (TLBO) algorithm is a new evolutional algorithm that has drawn a lot of attention of scientists and researchers, [30]. The principle of the method is based on the relationship between a teacher and learners. Like all heuristic algorithms, it is a population-based algorithm, where a group of students or a class is considered to be a population. The TLBO algorithm is divided into two characteristic phases: Teacher Phase and Learner Phase.

The mean value (the average value) of the quality of the class increases depending on a good teacher. A good teacher is the one who increases the knowledge of the students to their own level. This practically means that the progress of the class does not depend only on the teacher but also on the individual abilities of the students.

The best solution in an iteration will act as the teacher for that iteration. The teacher can be expressed as $X_{\text {Teacher }}$. Furthermore, the mean value $X_{\text {Mean }}$ for the overall solution has to be determined. The mean value is a new set of variables where each variable has a mean value in relation to the total number of students.

\subsection{Teacher Phase}

The first phase, called the Teacher Phase, refers to the influence of the teacher on the quality of the class. It depends directly on the mean value of the group, i.e. the population. Each teacher $X_{\text {Teacher }}$ will try to move the mean towards their own level $X_{\text {Mean }}$, so that a new mean value is created and designated as $X_{\text {New }}$. This value can be expressed as:

$$
X_{\text {New }, i}=X_{\text {Old }, i}+r_{i}\left(X_{\text {Teacher }}-T_{F} X_{\text {Mean }}\right)
$$

Here, $r$ stands for the random value in the range $(0,1) . T_{F}$ can be either 1 or 2 , which is decided randomly for each iteration. The value of the existing iteration is presented by the value $X_{\text {old }}$. This equation is applied in each iteration, but it is necessary to determine whether the newly acquired value is better that the old one. If the new value $X_{\text {New }}$ is better, it is accepted, otherwise the old one, $X_{\text {Old }}$, is kept. The best data set (set of variables) for each iteration will act as $X_{\text {Teacher }}$, which means that this value changes with the change in iterations.

\subsection{Learner Phase}

Learner Phase is the second phase of the TLBO algorithm, which is necessary for the proper functioning of the algorithm. It is based on interactions among the students. There are two possible cases in this phase. Two randomly chosen students are singled out. In the case when $X_{i}>X_{j}$ (the function values of the two randomly chosen students), the algorithm uses the following equation:

$$
X_{\text {New }}=X_{\text {Old }}+r\left(X_{i}-X_{j}\right)
$$

In the second case, when $X_{j}>X_{i}$, the algorithm employs the following expression:

$$
X_{\text {New }}=X_{\text {old }}+r\left(X_{j}-X_{i}\right)
$$


N. Kostić, M. Blagojević, N. Petrović, M. Matejić, N. Marjanović
Determination of Real Clearances Between Cycloidal Speed Reducer Elements by the Application of Heuristic Optimization

The random value $r$ is in the range of $(0,1)$, while the new value is accepted only if it is better than the previous one, regardless of which one of the cases is used.

\section{Test examples}

In order to verify the developed procedure, this paper gives representative practical examples based on the created mathematical model. A one-stage cycloidal speed reducer with corrected values is taken as an example. The cycloid disc has been corrected by $0.05 \mathrm{~mm}, 0.1$ $\mathrm{mm}$, and $0.3 \mathrm{~mm}$. These examples illustrate a possibility of applying the developed mathematical model, software, and the method in accordance with the actual requirements. The values of the actual cycloidal speed reducer needed for optimization are given in Table 1 .

Table 1 The values of the cycloidal speed reducer

\begin{tabular}{|l|l|l|}
\hline Description & Designation & Value \\
\hline Gear ratio & $u$ & 13 \\
\hline Radius of the rolling circle (mm) & $R_{a}$ & 6.143 \\
\hline Radius of the base circle (mm) & $R_{b}$ & 79.857 \\
\hline Eccentricity (mm) & $e$ & 4 \\
\hline Radius of the ring gear roller - equidistant distance (mm) & $q$ & 6.88 \\
\hline Number of the cycloid disc teeth & $z_{1}$ & 13 \\
\hline Number of the ring gear rollers & $z_{2}$ & 14 \\
\hline Auxiliary value & $R_{a}+R_{b}$ & 86 \\
\hline Auxiliary value & $R_{b} / R_{a}$ & 12.9996744 \\
\hline Auxiliary value & $R_{a} / e$ & 1.53571425 \\
\hline $\begin{array}{l}\text { Radius of the corrected ring gear roller - corrected equidistant distance } \\
\text { (mm) }\end{array}$ & $q_{c}$ & $6.83,6.78,6.58$ \\
\hline Size of the profile correction (mm) & $\Delta q=q-q_{c}$ & $0.05,0.1,0.3$ \\
\hline Angle between the two positions of the rollers (operation) & $\theta$ & 0.44879895 \\
\hline
\end{tabular}

With the theoretical model, all the teeth of the cycloid disc are in contact with the rollers, while half of the teeth carry the load, [1]. In order to solve the presented problem, the expression 5, which is an objective function, can be derived for the actual correction value of the cycloid disc profile. When minimization is performed for actual quantitative values of the objective function using the TLBO method, a set of potential solutions is obtained. These solutions refer to the values of the angle at which the contact between the cycloidal speed reducer elements is realized. Only the solutions where there is no overlapping between the cycloid disc and the ring gear rollers are acceptable.

\section{Results}

The mathematical model was formulated based on geometrical characteristics of the cycloidal speed reducer. For optimization purposes, original software based on TLBO was developed by the authors, and tested on standard test examples for validation.

The total number of evaluation functions was 250,000 , and the population size (the number of students) was 50 . The algorithm was run 100 times to determine potential solutions for which the ring gear roller was in contact with the cycloid disc. The distance between them had to be $0.0000000 \mathrm{~mm}$ ( 7 decimal places) to constitute contact.

The set of potential solutions include all cross-section points of the circle with the rollers and the cycloid disc. These values are given in Table 2. 
Determination of Real Clearances Between

Cycloidal Speed Reducer Elements by

N. Kostić, M. Blagojević, N. Petrović, the Application of Heuristic Optimization

Table 2 The set of potential contacts

\begin{tabular}{|c|c|c|c|c|c|c|c|c|}
\hline \multicolumn{9}{|c|}{ The set of solutions for the correction of $0.3 \mathrm{~mm}$} \\
\hline \multirow{3}{*}{$\begin{array}{l}\text { Angular position } \\
\text { of the roller in } \\
\text { contact }\left(^{\circ}\right)\end{array}$} & 12.431 & 14.015 & 38.261 & 41.406 & 63.970 & 69.876 & 89.631 & 99.838 \\
\hline & 115.224 & 131.585 & 140.602 & 219.406 & 228.426 & 244.784 & 260.172 & 270.377 \\
\hline & 290.133 & 296.039 & 318.603 & 321.747 & 345.994 & 347.578 & & \\
\hline \multicolumn{9}{|c|}{ The set of solutions for the correction of $0.1 \mathrm{~mm}$} \\
\hline \multirow{4}{*}{$\begin{array}{l}\text { Angular position } \\
\text { of the roller in } \\
\text { contact }\left(^{\circ}\right)\end{array}$} & 12.697 & 13.744 & 38.468 & 41.183 & 64.182 & 69.629 & 89.880 & 99.512 \\
\hline & 115.556 & 131.021 & 141.169 & 164.477 & 166.097 & 193.910 & 195.535 & 218.839 \\
\hline & 228.989 & 244.453 & 260.498 & 270.129 & 290.380 & 295.827 & 318.826 & 321.540 \\
\hline & 346.265 & 347.312 & & & & & & \\
\hline \multicolumn{9}{|c|}{ The set of solutions for the correction of $0.05 \mathrm{~mm}$} \\
\hline \multirow{4}{*}{$\begin{array}{c}\text { Angular position } \\
\text { of the roller in } \\
\text { contact }\left(^{\circ}\right)\end{array}$} & 12.773 & 13.666 & 38.520 & 41.127 & 64.235 & 69.568 & 89.941 & 99.432 \\
\hline & 115.637 & 130.889 & 141.302 & 163.854 & 166.721 & 193.287 & 196.158 & 218.706 \\
\hline & 229.121 & 244.372 & 260.578 & 270.067 & 290.441 & 295.774 & 318.882 & 321.488 \\
\hline & 346.343 & 347.235 & & & & & & \\
\hline
\end{tabular}

These solutions should be verified in order to make sure that there is no overlapping between any of the rollers and the cycloid disc. For this purpose, the developed optimization software and CAD software (Autodesk Inventor) were interactively applied. The optimization software was used to determine the absolute value of the distance of each roller from each cycloid disc, while the CAD software was used to create the parametric model for testing the optimization values to find out whether the distances were positive or negative, i.e. whether overlapping occurred between the elements. All the solutions for which at least one roller in Table 2 has a negative distance have to be rejected because they are not applicable in practice. In other words, if the cycloidal speed reducer elements are considered to be absolute rigid bodies, the contact is realized only between one tooth of the cycloid disc and the roller, while the rest of the teeth are at a certain distance from the ring gear roller. The roller No.3 in Table 3 is the only one in contact with the cycloid disc, while the rest of the rollers are numbered in positive mathematical direction. These solutions are acceptable for practical application.

Table 3 Clearances between the cycloidal speed reducer elements with corrected cycloid disc profiles

\begin{tabular}{|c|l|l|l|l|l|l|l|l|}
\hline \multicolumn{2}{|l|}{ Profile correction of 0.05mm } & \multicolumn{2}{l|}{ Profile correction of 0.1mm } & \multicolumn{3}{l|}{ Profile correction of 0.3mm } \\
\hline $\begin{array}{l}\text { Roller } \\
\text { number }\end{array}$ & $\begin{array}{l}\text { Roller } \\
\text { angle }\left(^{\circ}\right)\end{array}$ & $\begin{array}{l}\text { Distance from } \\
\text { cycloid disc } \\
(\mathrm{mm})\end{array}$ & $\begin{array}{l}\text { Roller } \\
\text { number }\end{array}$ & $\begin{array}{l}\text { Roller } \\
\text { angle }\left(^{\circ}\right)\end{array}$ & $\begin{array}{l}\text { Distance from } \\
\text { cycloid disc } \\
(\mathrm{mm})\end{array}$ & $\begin{array}{l}\text { Roller } \\
\text { number }\end{array}$ & $\begin{array}{l}\text { Roller } \\
\text { angle }\left(^{\circ}\right)\end{array}$ & $\begin{array}{l}\text { Distance from } \\
\text { cycloid } \\
(\mathrm{mm})\end{array}$ \\
\hline 1 & 38.520 & 0.0000000 & 1 & 38.468 & 0.0000000 & 1 & 38.261 & 0.0000000 \\
\hline 2 & 64.234 & 0.0001034 & 2 & 64.182 & 0.0006017 & 2 & 63.975 & 0.0055156 \\
\hline 3 & 89.949 & 0.0063563 & 3 & 89.897 & 0.0139653 & 3 & 89.690 & 0.0468390 \\
\hline 4 & 115.663 & 0.0163896 & 4 & 115.611 & 0.0341669 & 4 & 115.404 & 0.1077171 \\
\hline 5 & 141.377 & 0.0288215 & 5 & 141.325 & 0.0588210 & 5 & 141.118 & 0.1811158 \\
\hline 6 & 167.092 & 0.0427985 & 6 & 167.040 & 0.0862049 & 6 & 166.833 & 0.2618805 \\
\hline 7 & 192.806 & 0.0575030 & 7 & 192.754 & 0.1147003 & 7 & 192.547 & 0.3452111 \\
\hline 8 & 218.520 & 0.0720919 & 8 & 218.468 & 0.1426730 & 8 & 218.261 & 0.4263282 \\
\hline 9 & 244.234 & 0.0856738 & 9 & 244.182 & 0.1684298 & 9 & 243.975 & 0.5003464 \\
\hline 10 & 269.949 & 0.0972395 & 10 & 269.897 & 0.1900837 & 10 & 269.690 & 0.5618578 \\
\hline 11 & 295.663 & 0.1053207 & 11 & 295.611 & 0.2048959 & 11 & 295.404 & 0.6028518 \\
\hline 12 & 321.377 & 0.1060969 & 12 & 321.325 & 0.2055595 & 12 & 321.118 & 0.5998447 \\
\hline 13 & 347.092 & 0.0810017 & 13 & 347.040 & 0.1548181 & 13 & 346.833 & 0.4091832 \\
\hline 14 & 372.806 & 0.0201856 & 14 & 372.754 & 0.0377965 & 14 & 372.547 & 0.0913279 \\
\hline
\end{tabular}

The TLBO algorithm is obviously an extraordinary optimization method suitable for solving engineering optimization problems. The adopted evaluation value of 250,000 , with a 
N. Kostić, M. Blagojević, N. Petrović, M. Matejić, N. Marjanović
Determination of Real Clearances Between Cycloidal Speed Reducer Elements by the Application of Heuristic Optimization

population of 50 yields an optimal solution in all 30 runs for all the three corrections of the cycloid disc profile.

For the solutions given in Table 3, only one ring gear roller is in contact with the cycloid disc and the distance between them is $0 \mathrm{~mm}$. There are clearances between other rollers and the cycloid disc. Fig. 6 shows clearances between these elements in all the three cases.

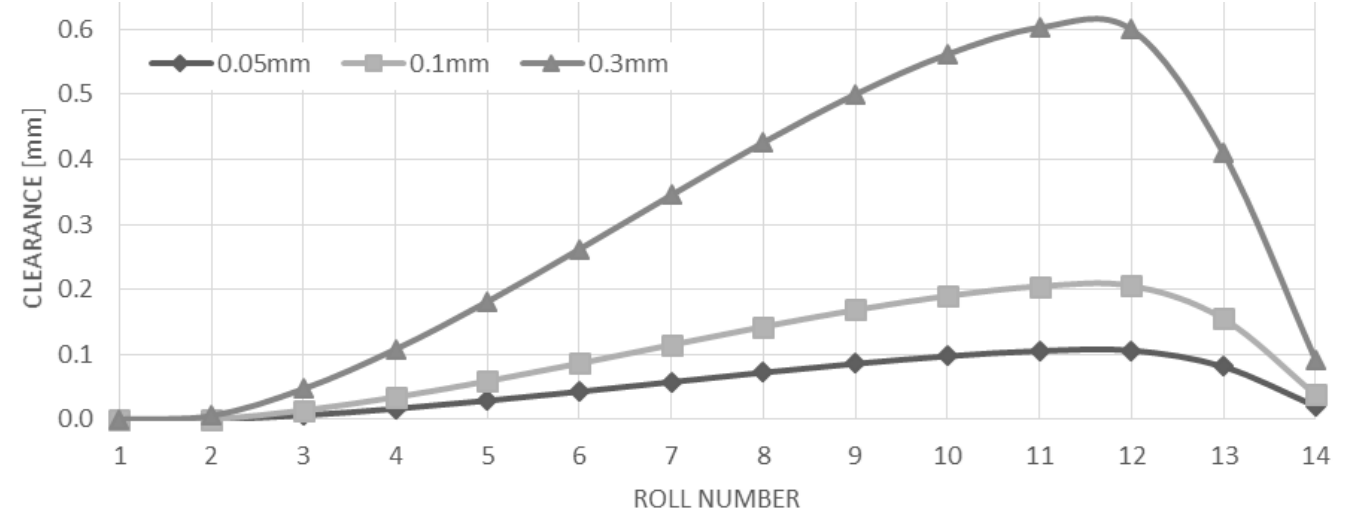

Fig. 6 Clearances between the ring gear rollers and the cycloid disc for corrections of $0.05 \mathrm{~mm}, 0.1 \mathrm{~mm}$, and $0.3 \mathrm{~mm}$

The correction values were chosen to demonstrate the methodological procedure of value determination and to illustrate the fact that corrections can be done for any value, depending on the actual machining tolerances and manufacturing conditions. Figure 7 shows the contact position with the corrected cycloid disc contacts. The circle with the centres of the ring gear rollers is turned until the contact is established.

There are many potential applications of these results and there is a possibility to directly integrate this procedure into CAD software. This would enable the design and analysis of cycloidal speed reducers with contacts and clearances that actually occur in practice. Real clearences could vary as a result of elastic deformation.

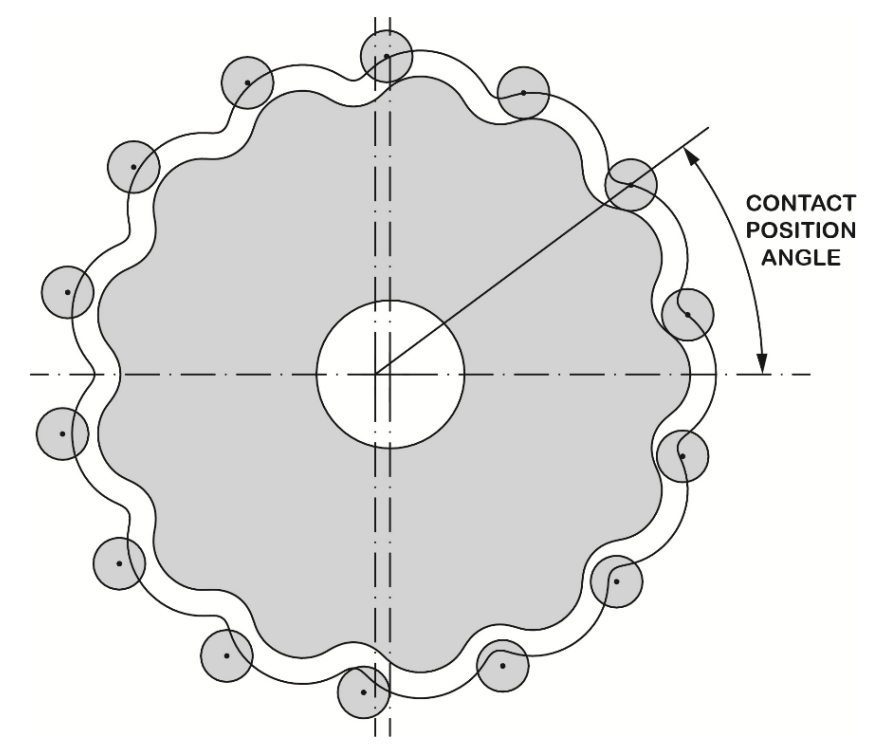

Fig. 7 Contact position based on the optimization solutions

\section{Conclusion}

The prime motive for conducting research in this filed is a great desire and need for practical and efficient use of alternative gear trains. Better knowledge of cycloidal speed reducers ensures their better practical applications. In addition, there is also a need to use optimization methods to solve machine design problems. A heuristic approach that enables 
finding a solution to complex engineering problems in a simple way was employed for the purpose of this research.

The solution to the problem of how to determine clearances in the cycloidal speed reducer elements makes a significant step forward in the practical application of non-involute gears. This analysis also contributes to improvements in the performance of cycloidal gears and the reduction in manufacturing costs through finding a lower precision level required in production.

Clearances between the cycloidal speed reducer elements when one roller is in contact with the cycloid disc were determined by applying the TLBO methods. Based on the geometrical properties, an original mathematical model for determination of the distance between the elements of the cycloidal speed reducer was created. The correction of the profile was done for $0.05 \mathrm{~mm}, 0.1 \mathrm{~mm}$, and $0.3 \mathrm{~mm}$ in order to validate the developed procedure and in order to demonstrate that it is possible to determine clearances for any correction value. The approach presented here has been developed so that researches can analyse a real cycloidal speed reducer with only one roller in contact with the cycloid disc and not a theoretical model. This is very important because it is not possible to manufacture elements with no tolerances and no manufacturing errors. This also affects the stress and strain state, but that will be the object of our further investigations which will also include the effects of elastic deformation on clearances. Finally, this process can be automated in order to facilitate its application.

\section{Acknowledgment}

This paper is a result of the projects TR33015 of the Technological Development of Republic of Serbia, titled "Investigation and development of Serbian zero-net energy house", and TR32036 "Software development for solving coupled multiphysics problems". We would like to thank to the Ministry of Education, Science and Technological Development of Republic of Serbia for their financial support during this research.

\section{REFERENCES}

[1] Kudrijavcev, V.N., 1966, Planetary Gear Train (in Russian), Mechanical Engineering, Leningrad.

[2] Lehmann, M., 1976, Calculation and Measurement of Forces Acting on Cycloid Speed Reducer (in German), PhD Thesis, Technical University Munich, Germany.

[3] Malhotra, S.K., Parameswaran M. A., 1983, Analysis of a Cycloid Speed Reducer, Mechanism and Machine Theory, Vol. 18, No. 6, pp. 491-499. https://doi.org/10.1016/0094-114X(83)90066-6

[4] Lin, W.S., Shin, Y.P., Lee, J.J., 2014, Design of a Two-Stage Cycloidal Gear Reducer with Tooth Modifications, Mechanism and Machine Theory, Vol. 79, pp. 184-197. https://doi.org/10.1016/j.mechmachtheory.2014.04.009

[5] Hwang, Y.W., Hsieh, C.F., 2007, Geometric Design Using Hypotrochoid and Nonundercutting Conditions for an Internal Cycloidal Gear, Journal of Mechanical Design, Vol. 129, pp. 413-420. https://doi.org/10.1115/1.2437806

[6] Li, X., Chen, B., Wang, Y., Sun, G., Lim, T. 2015, Geometry Design of a Non - Pin Cycloid Drive for In - Wheel Motor, SAE International.

[7] Yan, H.S., Lai, T.S. 2002, Geometry Design of an Elementary Planetary Gear Train with Cylindrical Tooth-Profiles, Mechanism and Machine Theory, Vol. 37, pp. 757-767. https://doi.org/10.1016/S0094$114 \mathrm{X}(02) 00009-5$

[8] Hwang, Y.W., Hsieh, C.F. 2006, Geometry Design and Analysis for Trochoidal - Type Speed Reducers: with Conjugate Envelopes, Transactions of the CSME/de la SCGM, Vol. 30, No. 2, pp. 261-278.

[9] Chen, B.K., Fang, T.T., Li, C.Y., Wang, S.Y. 2008, Gear Geometry of Cycloid Drives, Science in China Series E: Technological Sciences, Vol. 51,No. 5, pp. 598-610. https://doi.org/10.1007/s11431-008-0055-3

[10] Blagojević, M., 2008, Stress and Strain State of Cyclo Speed Reducer`s Elements Under Dynamic Loads (in Serbian), PhD Thesis, Faculty of Mechanical Engineering, Kragujevac, Serbia.

[11] Shin, J.H., Kwon, S.M., 2006, On the Lobe Profile Design in a Cycloid Reducer Using Instant Velocity Center, Mechanism and Machine Theory, Vol. 41, pp. 596-616. https://doi.org/10.1016/j.mechmachtheory.2005.08.001

[12] Dascalescu, A., Ungureanu, M. 2010, CAD - CAM Programs Applied to the Cycloid Profile Wheels Processing, Annals of the University of Petrosani, Mechanical Engineering, Vol. 12, pp. 65-70. 
[13] Li, S., 2014, Design and Strength Analysis Methods of the Trochoidal Gear Reducers, Mechanism and Machine Theory, Vol. 81, pp. 140-154. https://doi.org/10.1016/j.mechmachtheory.2014.07.001

[14] Sensinger, J., 2010, Unified Approach to Cycloid Drive Profile, Stress, and Efficiency Optimization, Journal of Mechanical Design,Vol.132, pp.024503-1-024503-5. https://doi.org/10.1115/1.4000832

[15] Qian, X.Y., Zou, L., Guo, B. 2010, Multi - Objective Moderate Optimization in Cycloid Drive, International Conference on Digital Manufacturing \& Automation, pp. 968-971. https://doi.org/10.1109/ICDMA.2010.131

[16] Chen, B., Zhong, H., Liu, J., Li, C., Fang, T., 2012, Generation and Investigation of a New Cycloid drive with Double Contact, Mechanism and Machine Theory, Vol.49, pp.270-283. https://doi.org/10.1016/j.mechmachtheory.2011.10.001

[17] Blagojevic, M., Marjanovic, N., Djordjevic, Z., Stojanovic, Z., Disic, A., 2011, A New Design of a TwoStage Cycloidal Speed Reducer, Journal of Mechanical Design,Vol.133, No. 8. https://doi.org/10.1115/1.4004540

[18] Hsieh, C.F., 2014, The Effect on Dynamics of Using a New Transmission Design for Eccentric Speed Reducer, Mechanism and Machine Theory,Vol.80, pp. 1-16. https://doi.org/10.1016/j.mechmachtheory.2014.04.020

[19] Hsieh, C.F., 2015, Traditional Versus Improved Designs for Cycloidal Speed Reducers with a Small Tooth Difference: The Effect on Dynamics, Mechanism and Machine Theory, Vol. 86, pp. 15-35. https://doi.org/10.1016/j.mechmachtheory.2014.11.013

[20] Gu I., 1998, Design of Antibacklash Pin-Gearing, Journal of Mechanical Design, Vol. 120, pp. 133-138. https://doi.org/10.1115/1.2826665

[21] Blanche, J.G., Yang, D.C.H., 1989, Cycloid Drives with Machining Tolerances, Journal of Mechanisms, Transmissions, and Automation in Design, Vol. 111, pp. 337-344. https://doi.org/10.1115/1.3259004

[22] Yang, D.C.H., Blanche, J.G., 1990, Design and Application Guidelines for Cycloid Drives with Machining Tolerances, Mechanism and Machine Theory, Vol. 25, No. 5, pp. 487-501. https://doi.org/10.1016/0094-114X(90)90064-Q

[23] Lixing, L., Xin, L., Weidong, H., Yuanmei, Q., 1999, Profile Modification and Accurate Force Analysis on Cycloid Drive, World Congress on Gearing and Power Transmission, March16-18, Paris, France.

[24] Kao, W.P., Hsieh, C.C., Lee, J.J. 2015, Computer-Aided Kinematic Error Analysis of a Two-Stage Cycloidal Drive, The 14th IFToMM World Congress, October 25-30, Taipei, Taiwan.

[25] Stefanović-Marinović, J., Petković, M., Stanimirović, I., Milovančević, M., 2011, A Model of Planetary Gear Multicriteria Optimization, Transactions of FAMENA XXXV-3, Vol. 35, No. 4, pp. 21-34.

[26] Maruda, R. W., Krolczyk, G.M., Nieslony, P., Wojciechowski, S., Michalski, M., Legutko, S., 2016, The influence of the cooling conditions on the cutting tool wear and the chip formation mechanism, Journal of Manufacturing Processes, 24P1, pp. 107-115.

[27] Stefanović-Marinović, J., Petković, M., Stanimirović, I., 2015, Application of The Electre Method to Planetary Gear Train Optimization, Journal of Mechanical Science and Technology, Vol. 29, No. 2, pp. 647-654. https://doi.org/10.1007/s12206-015-0124-Z

[28] Wojciechowski, S., Maruda, R. W., Nieslony, P., Krolczyk, G.M., 2016, Investigation on the edge forces in ball end milling of hardened steel, International Journal of Mechanical Sciences, 119, pp. 360-369. https://doi.org/10.1016/j.ijmecsci.2016.10.034

[29] Królczyk, G., Legutko, S., Raos, P., 2013, Cutting wedge wear examination during turning of duplex stainless steel, Tehnički Vjesnik - Technical Gazette, Vol. 20, No. 3, pp. 413-418.

[30] Rao R.V., Savsani V.J., Vakharia D.P., 2012, Teaching-Learning-Based Optimization: An optimization method for continuous non-linear large scale problems, Information Sciences, Vol. 183, p.p. 1-15. https://doi.org/10.1016/j.ins.2011.08.006

[31] Rao R.V., Savsani V.J., Vakharia D.P., 2011, Teaching-learning-based optimization: A novel method for constrained mechanical design optimization problems, Computer-Aided Design, Vol. 43, p.p. 303-315. https://doi.org/10.1016/j.cad.2010.12.015

Submitted: $\quad 07.2 .2017$

Accepted: $\quad 30.8 .2017$
Nenad Kostić

Mirko Blagojević

Nenad Petrović

Miloš Matejić

Nenad Marjanović

University of Kragujevac, Faculty of

Engineering

Sestre Janjić 6, 34000 Kragujevac, Serbia 